\title{
Causes of death in intermediate-risk patients: The Randomized Surgical Replacement and Transcatheter Aortic Valve Implantation Trial
}

\author{
Hafid Amrane, MD, ${ }^{a}$ G. Michael Deeb, MD, ${ }^{b}$ Jeffrey J. Popma, MD, ${ }^{c}$ Steven J. Yakubov, MD, \\ Thomas G. Gleason, MD, ${ }^{e}$ Nicolas M. Van Mieghem, MD, PhD, ${ }^{f}$ and Michael J. Reardon, MD, ${ }^{g}$ the \\ SURTAVI Trial Causes of Death Working Group
}

\section{ABSTRACT}

Objectives: Examine the causes and timing of death in the Surgical Replacement and Transcatheter Aortic Valve Implantation intermediate-risk randomized trial for transcatheter aortic valve replacement (TAVR) and surgical aortic valve replacement (SAVR).

Methods: Causes of death were adjudicated by an independent clinical event committee and by post-hoc hierarchical classification. Causes of death were evaluated and characteristics and procedural parameters compared between patients who died and survivors for 3 time periods: early (0-30 days), recovery (31120 days), and late (121-365 days).

Results: All-cause mortality at 1 year was $6.5 \%$ after TAVR and $6.7 \%$ after SAVR. There were no differences in mortality rates between TAVR and SAVR for any of the 3 time periods. Early mortality was primarily due to technical, procedure-related problems in TAVR and due to complications in SAVR. For TAVR and SAVR, most deaths during recovery were caused by complications. Other causes, including comorbid conditions, accounted for most late deaths.

Conclusions: Mortality rates were similar for patients treated with TAVR or SAVR at any time period including at 1 year. Early cause of death was more commonly technical failure after TAVR and due to complications after SAVR. Recovery phase cause of death was dominated by complications from TAVR and SAVR. Late cause of death appeared to be independent of the procedure in both groups. (J Thorac Cardiovasc Surg 2019;158:718-28)

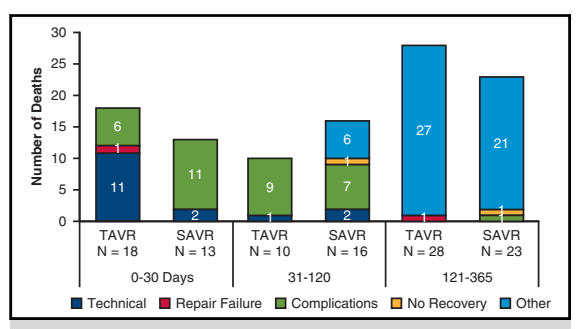

Hierarchical causes of death after TAVR and SAVR for 3 time periods through 1 year.

\section{Central Message}

Mortality in intermediate-risk TAVR and SAVR patients is similar and driven by technical, procedural problems in TAVR and complications from SAVR.

\section{Perspective}

This analysis found similar survival for intermediate-risk patients undergoing TAVR and SAVR during 3 time periods through 1 year. Results suggest that survival may primarily be improved by prevention of technical, procedural problems in TAVR (reducing early death) and prevention of complications after TAVR and SAVR (reducing deaths within 30 days), and during the recovery period after TAVR and SAVR.

See Commentary on page 729 .
Transcatheter aortic valve replacement (TAVR), first performed in $2002,{ }^{1}$ was initially intended as an alternative treatment for severe, symptomatic aortic stenosis (AS) in

\footnotetext{
From the ${ }^{\mathrm{a}}$ Department of Cardiac and Thoracic Surgery, Medisch Centrum Leeuwarden, The Netherlands; ${ }^{b}$ Department of Cardiac Surgery, University of Michigan Hospitals, Ann Arbor, Mich; ${ }^{\mathrm{c} D e p a r t m e n t ~ o f ~ I n t e r v e n t i o n a l ~ C a r d i o l o g y, ~ B e t h ~ I s r a e l ~}$ Deaconess Medical Center, Harvard Medical School, Boston, Mass; ${ }^{\mathrm{d}}$ Department of Interventional Cardiology; Riverside Methodist-Ohio Health, Columbus, Ohio; e Department of Cardiothoracic Surgery, University of Pittsburgh Medical Center, Pittsburgh, Pa; ${ }^{\mathrm{f}}$ Department of Interventional Cardiology, Eramus Medical Center, Rotterdam, The Netherlands; and ${ }^{\mathrm{g}}$ Department of Cardiothoracic Surgery, Houston Methodist DeBakey Heart \& Vascular Center, Houston, Tex.

Funding for this study was provided by Medtronic, Minneapolis, Minn.

Members of the Surgical Replacement and Transcatheter Aortic Valve Implantation Trial Causes of Death Working Group are listed in the Acknowledgments.
}

patients unable to undergo surgery. Randomized controlled trials in patients deemed inoperable, or at extreme or high surgical risk have consistently shown TAVR to have

\footnotetext{
Read at the 98th Annual Meeting of The American Association for Thoracic Surgery, San Diego, California, April 28-May 1, 2018.

Received for publication April 24, 2018; revisions received Oct 31, 2018; accepted for publication Nov 5, 2018; available ahead of print Jan 29, 2019.

Address for reprints: Michael J. Reardon, MD, Department of Cardiothoracic Surgery, Houston Methodist DeBakey Heart \& Vascular Center, Houston, TX (E-mail: mreardon@houstonmethodist.org). $0022-5223 / \$ 36.00$

Copyright $(2018$ by The American Association for Thoracic Surgery https://doi.org/10.1016/j.jtcvs.2018.11.129
} 

Abbreviations and Acronyms
$\mathrm{AF} \quad=$ atrial fibrillation
AKI $=$ acute kidney injury
AS $=$ aortic stenosis
CEC $=$ Clinical Event Committee
MI $=$ myocardial infarction
PPM = patient-prosthesis mismatch
SAVR = surgical aortic valve replacement
STS PROM $=$ Society of Thoracic Surgeons
Predicted Risk of Mortality
SURTAVI = Surgical Replacement and
Transcatheter Aortic Valve
Implantation
TAVR $=$ transcatheter aortic valve replacement

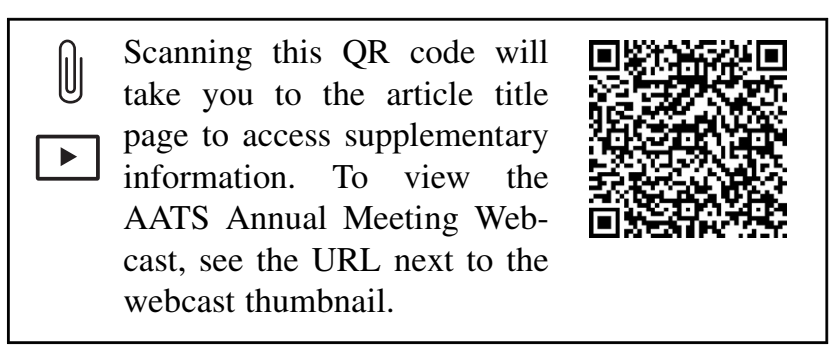

comparable, if not superior, survival compared with medical management or surgery. ${ }^{2-4}$ Recently, 2 randomized trials in patients at intermediate surgical risk have shown TAVR to be noninferior for the end point of mortality or disabling stroke to surgery. ${ }^{5,6}$ As TAVR is applied in patients with lower surgical risk, the differences in outcomes between patients undergoing surgical aortic valve replacement (SAVR) and TAVR may become less pronounced.

In the CoreValve US Pivotal High Risk Trial, TAVR was associated with superior survival compared with SAVR at 1 year, ${ }^{2}$ and the differences in mortality between the 2 treatment groups were most distinct in patients who died 1 to 4 months postprocedure. ${ }^{7}$ Gaudiani and colleagues ${ }^{7}$ showed that high-risk patients treated with SAVR during this period died primarily due to a failure to adequately repair the AS or the inability to recover from the more invasive procedure, and patients treated with TAVR were influenced by procedure-related complications.

The Surgical Replacement and Transcatheter Aortic Valve Implantation (SURTAVI) trial randomized patients with severe symptomatic AS at intermediate surgical risk to either TAVR with a self-expanding valve, or SAVR. TAVR was shown to be noninferior to SAVR for the primary end point of all-cause mortality or disabling stroke. ${ }^{6}$
The number of patients in the United States and Germany being treated with TAVR has recently surpassed those treated with SAVR. ${ }^{8,9}$ With TAVR currently being studied in younger patients at low surgical risk (ClinicalTrials.gov identifiers: NCT02675114 and NCT02701283), the proportion of patients undergoing TAVR will likely expand if the trials show positive results. We hypothesized that the causes of death for TAVR and SAVR patients are different at different time periods and understanding this will allow us to focus on mitigating these and improving survival. The objective of this report is to examine the timing and causes of death in the first year postprocedure for patients treated with TAVR or SAVR in the SURTAVI trial.

\section{METHODS \\ Study Overview}

The present study is a post hoc analysis of the SURTAVI trial. The SURTAVI trial was a randomized, controlled, noninferiority trial performed at 87 sites in Canada, Europe, and the United States, comparing the safety and efficacy of TAVR versus SAVR in patients with symptomatic, severe AS at intermediate surgical risk. Details of the study design and primary outcomes have been previously reported. ${ }^{6}$ In brief, eligible patients were randomized to TAVR or SAVR, with randomization stratified by clinical site and the need for coronary revascularization. An independent Clinical Events Committee (CEC) adjudicated all major clinical events, including cause of death, and study oversight was provided by an independent data safety monitoring board. The SURTAVI study protocol was approved by each local institutional review board or medical ethics committee. All patients provided written informed consent.

\section{Patients}

Patient selection procedures and details of the study population have been previously described. ${ }^{6}$ In brief, patients with severe symptomatic AS who were deemed to be at intermediate surgical risk (a Society of Thoracic Surgeons Predicted Risk of Mortality [STS PROM] 3\%-15\%) were eligible to participate in SURTAVI. Other non-STS factors, such as frailty, were also considered. An international screening committee reviewed each patient to determine eligibility for TAVR.

\section{Procedure Details}

Patients randomized to SAVR underwent surgical valve replacement and coronary revascularization if indicated. The type and size of the bioprosthetic valve were based on operator preference. Patients randomized to the TAVR group received a 23-, 26-, 29-, or 31-mm CoreValve (Medtronic, Minneapolis, Minn) or a 23-, 26-, or $29 \mathrm{~mm}$ Evolut R selfexpanding bioprosthesis (Medtronic), preferably by transfemoral access. The size of the bioprosthesis was based on preprocedural multidetector computed tomography. If indicated, percutaneous coronary intervention was performed either as a staged procedure before TAVR or as a concomitant intervention during TAVR.

\section{Analysis}

The analysis cohort for this report comprised 1660 patients who underwent attempted implant from June 2012 to June 2016 of a transcatheter ( $\mathrm{n}=864)$ or surgical $(\mathrm{n}=796)$ bioprosthesis based on randomization. Deaths occurring through July 29, 2017, are reported. In addition to the CEC adjudication, individual patient histories were retrospectively reviewed by 2 cardiovascular surgeons (HA and MJR) to classify the cause of death in a hierarchical fashion, consistent with the method applied by 
Gaudiani and colleagues. ${ }^{7}$ Recognizing that the final cause of death is often the result of a chain of events that may be initiated before the actual death of a patient, the most probable initiating factor was determined using 5 hierarchical categories (Table 1). Patient deaths were distributed based on 3 time periods: early ( $0-30$ days, with day 0 the day of the procedure), recovery (31-120 days), and late (121-365 days). ${ }^{7}$ The analysis for each time period included patients with known death or survivals at the start and end of the time period.

Categorical variables are presented as numbers and percentages and compared with Fisher exact test or the $\chi^{2}$ test where appropriate. Continuous variables are presented as mean \pm standard deviation and compared with the Student $t$ test. Estimates of all-cause mortality were determined by the Kaplan-Meier method for each time period. The number at risk for each time period included patients with known status at the start of the time period. For each time period, baseline characteristics, procedure outcomes, and clinical outcomes were compared between those who died and survived. The instantaneous hazard function was estimated from the nonparametric Kaplan-Meier survival function using the Epanechnikov kernel smoothing method with a bandwidth of 25 grid points. For any comparison between groups, a $P$ value $<.05$ was considered to indicate statistical significance. All statistical analyses were performed with the use of SAS software, version 9.4 (SAS Institute Inc, Cary, NC).

\section{RESULTS}

Overall baseline characteristics have been previously reported and showed no difference between the TAVR and SAVR groups. ${ }^{6}$ The mean age for patients in the SAVR group was $79.7 \pm 6.1$ years and for the TAVR patients it was $79.9 \pm 6.2$ years. The mean STS PROM was $4.5 \% \pm 1.6 \%$ in the SAVR group and $4.4 \% \pm 1.5 \%$ in the TAVR group. There were 438 men $(55.0 \%)$ in the SAVR group and 498 men $(57.6 \%)$ in the TAVR group. All patients in the SURTAVI trial now have completed 1year follow-up. A total of 56 patients in the TAVR group died $(6.5 \%)$ and 52 patients in the SAVR group died $(6.5 \%)$ during the first year postprocedure. The instantaneous risk of death, estimated by the hazard function, is shown in Figure 1. The distribution of the hierarchical causes of death after TAVR and SAVR for the 3 time periods are shown in Figure 2 and discussed in detail below.

\section{Early Mortality (0-30 Days)}

Within the first 30 days postprocedure 31 patients died: 18 patients in the TAVR group $(2.1 \%)$ and 13 patients in the SAVR group $(1.6 \%)(P=.50)$ (Table 2). There were 846 survivors in the TAVR group and 778 survivors in the SAVR group (Table 3). Within the immediate postprocedure period ( $\leq 72$ hours) 9 patients died: 5 in the TAVR group and 4 in the SAVR group. More than 1 valve was implanted in 58 patients ( $6.7 \%$ of the TAVR group); 57 in the patients treated with the CoreValve bioprosthesis and 1 treated with the Evolut R valve. A detailed comparison of baseline characteristics and procedural outcomes between patients who died and those who survived during each of the follow-up periods is presented in the Table E1. There were no differences in baseline characteristics for the patients in the TAVR group who died in the first 30 days
TABLE 1. Hierarchical classification of the causes of death*

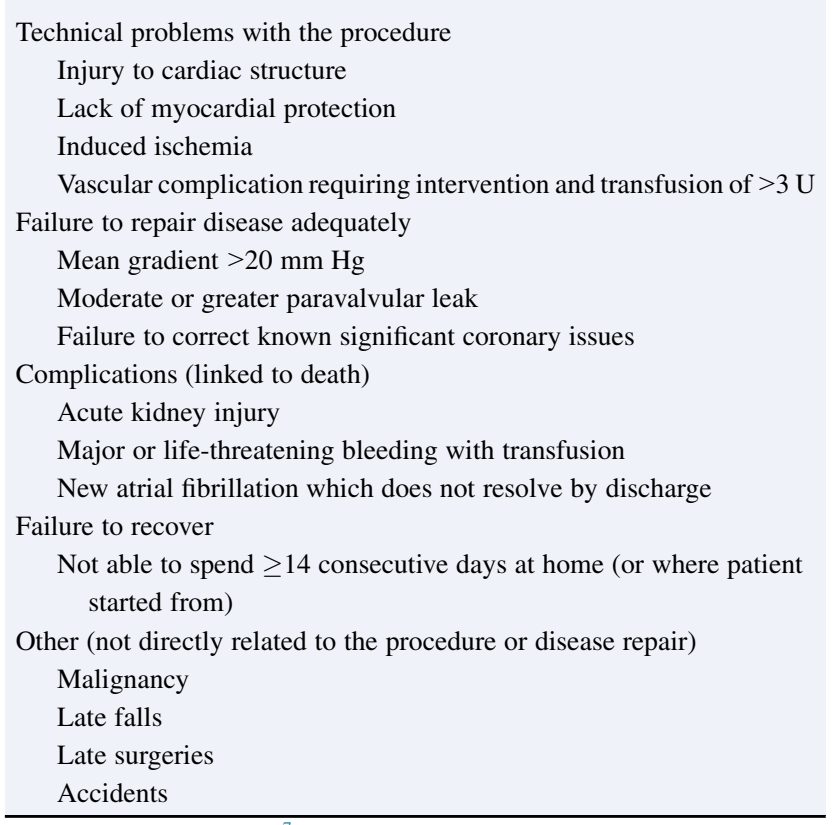

*Reprinted with permission.

postprocedure compared with those who survived. For the patients in the SAVR group who died versus those who survived within the first 30 days, more patients who died had a history of cerebrovascular disease $(46.2 \%$ vs $15.8 \%$; $P=.003)$ and home oxygen use $(15.4 \%$ vs $2.4 \% ; P=.04)$. Procedure differences. More patients in the TAVR group who died within the first 30 days required revascularization $(41.2 \%$ vs $19.1 \% ; P=.02)$, had more than 1 valve implanted $(23.5 \%$ vs $6.4 \% ; P=.02)$ and had a significantly longer procedure time $(93.8 \pm 62.3$ minutes vs $51.6 \pm 31.5$ minutes; $P=.02$ ). There were no significant procedure-related differences in the SAVR group, yet 1 patient died in the early period due to annular disruption.

Clinical outcomes at 30 days. Major clinical outcomes for patients who died and survived are shown in Table 3. Compared with survivors, patients who died in the TAVR group had a higher incidence of new stroke, atrial fibrillation (AF), myocardial infarction (MI), acute kidney injury (AKI), major vascular complications, coronary obstruction, and procedural conversion. Patients in the TAVR group who died during this early period also more often received a transfusion $66.7 \%$ vs $12.9 \% ; P<.001)$. Patients who died in the SAVR group more often had a new disabling stroke, major vascular complication, AKI, MI, and procedural conversion (Table 3).

Causes of death. The causes of death based on the CEC adjudication are shown in Table 4. All early deaths were due to cardiovascular causes, except for 1 patient in the TAVR group who died due to infection/sepsis. In both groups, procedural complications were the most frequent 


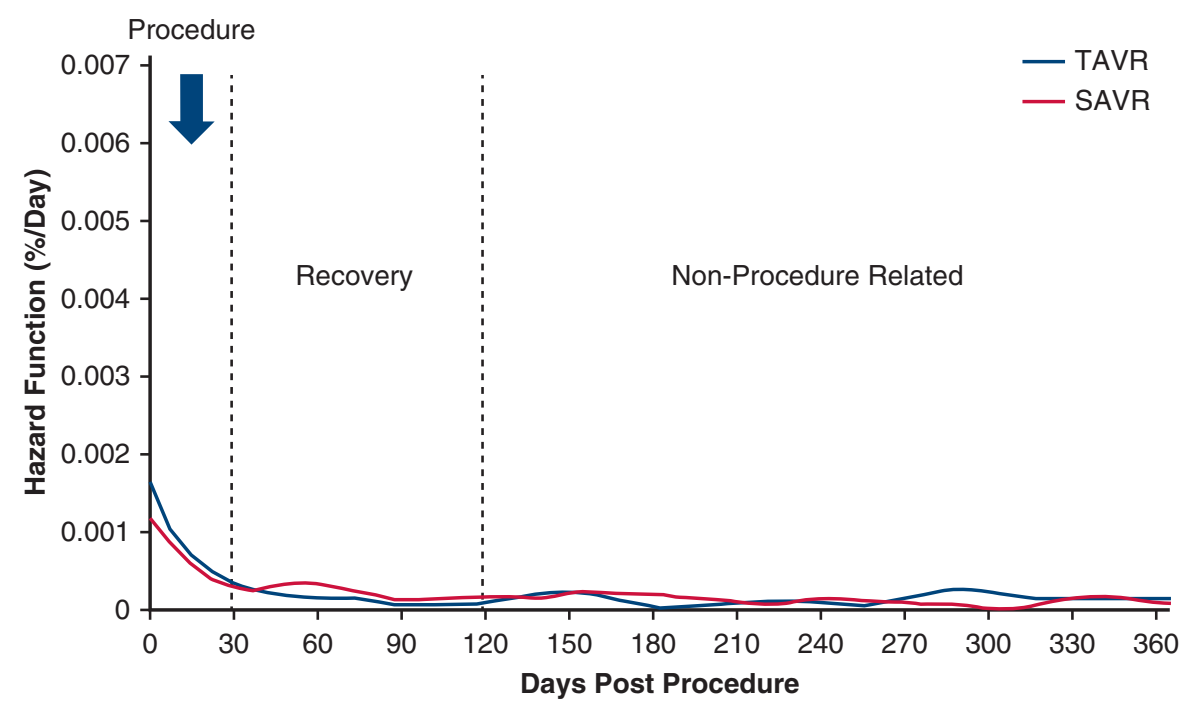

FIGURE 1. Instantaneous hazard curve of all-cause mortality after transcatheter aortic valve replacement (TAVR) and surgical aortic valve replacement (SAVR). The instantaneous hazard function was estimated from the nonparametric Kaplan-Meier survival function using the Epanechnikov kernel smoothing method with a bandwidth of 25 grid points.

cause of death, but this cause was more common in the TAVR group than in the SAVR group $(61.1 \%$ vs $38.5 \%)$. By hierarchical classification (Table 4), the most frequent causes of death among TAVR patients were technical procedure-related issues in 11 patients $(61.1 \%)$ followed by fatal complications in 6 patients $(33.3 \%)$, while 11 of $13(84.6 \%)$ among SAVR patients were due to complications (Figure 2).

\section{Recovery Period Mortality (31-120 Days)}

During the recovery period, 10 patients in the TAVR group $(1.2 \%)$ and 16 patients in the SAVR group $(2.1 \%)$ died $(P=.16)$ (Table 2$)$. There were 833 survivors in the TAVR group and 753 survivors in the SAVR group

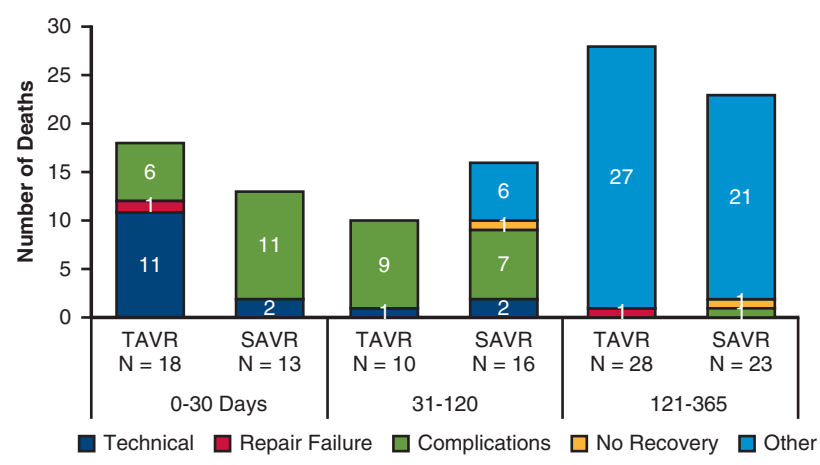

FIGURE 2. The number of deaths in each follow-up period based on the 5 hierarchical causes of death categories defined by Gaudiani and colleagues ${ }^{7}$ are shown for the transcatheter aortic valve replacement (TAVR) and surgical aortic valve replacement $(S A V R)$ patients. Table 1 shows the types of deaths include in each of the 5 categories.
(Table 3). Patients who died in the TAVR group during the recovery period had a significantly higher STS PROM score compared with those who survived $(5.5 \% \pm 2.0 \%$ vs $4.4 \% \pm 1.5 \% ; P=.02$ ) (Table E1).

Clinical outcomes from 31 to 120 days. Compared with survivors, patients who died in the TAVR group had a higher incidence of disabling stroke, vascular complication, MI, and aortic valve-related hospitalization (Table 3). Patients in the SAVR group who died had a higher incidence of reintervention, stroke, major bleeding, endocarditis, new or worsening AF, AKI, and MI.

Causes of death from 31 to 120 days. Most deaths were due to cardiovascular causes $(70 \%$ and $75 \%$ in the TAVR and SAVR group, respectively) with none of the subcategories being highly predominant (Table 4). All 3 noncardiovascular deaths in the TAVR group were due to infection/sepsis. By hierarchical classification (Table 4), complications were the most frequent cause of death in both groups $(90.0 \%$ and $43.8 \%$ in the TAVR and SAVR group, respectively), although $37.5 \%$ of deaths in SAVR patients were classified as Other (ie, not directly related to the procedure or disease repair).

\section{Late Mortality (121-365 Days)}

During the late period, 28 patients $(3.4 \%)$ in the TAVR group died and 23 patients $(3.1 \%)$ in the SAVR group died $(P=.76)$ (Table 2$)$. There were 777 survivors in the TAVR group and 691 survivors in the SAVR group (Table $3)$. The only differences in baseline characteristics for those who died compared to survivors was a significantly higher STS PROM score in the TAVR patients who died $(5.1 \% \pm 1.6 \%$ vs $4.4 \% \pm 1.5 \% ; P=.01)$ and more 
TABLE 2. Mortality rates for patients in the transcatheter aortic valve replacement (TAVR) and surgical aortic valve replacement (SAVR) groups for each of the 3 time periods

\begin{tabular}{|c|c|c|c|c|c|c|c|c|c|}
\hline & \multicolumn{3}{|c|}{0 to $30 \mathrm{~d}$} & \multicolumn{3}{|c|}{31 to $120 \mathrm{~d}$} & \multicolumn{3}{|c|}{121 to $365 d$} \\
\hline & $\overline{T A V R}$ & SAVR & $P$ value ${ }^{*}$ & $\overline{T A V R}$ & SAVR & $P$ value $*$ & TAVR & SAVR & $P$ value* \\
\hline All-cause mortality & $18(2.1)$ & $13(1.6)$ & .50 & $10(1.2)$ & $16(2.1)$ & .16 & $28(3.4)$ & $23(3.1)$ & .76 \\
\hline Cardiovascular & $17(2.0)$ & $13(1.6)$ & .61 & $7(0.8)$ & $12(1.6)$ & .18 & $16(2.0)$ & $16(2.2)$ & .76 \\
\hline Noncardiovascular & $1(0.1)$ & $0(0.0)$ & .34 & $3(0.4)$ & $4(0.5)$ & .62 & $12(1.5)$ & $7(1.0)$ & .36 \\
\hline
\end{tabular}

Values are presented as n (Kaplan-Meier rates as percentage). TAVR, Transcatheter aortic valve replacement; SAVR, surgical aortic valve replacement. *Based on log-rank test.

patients who died in the SAVR group had a history of AF $(56.5 \%$ vs $25.6 \% ; P=.001)$.

Clinical outcomes from 121 to 365 days. In the TAVR group, the incidence of disabling stroke, MI, major bleeding, and aortic valve-related hospitalizations were significantly higher in the patients who died 121 to 365 days postprocedure (Table 3). For the SAVR group, the incidence of stroke and endocarditis were significantly higher in the patients who died.

Causes of death from 121 to 365 days. Like the recovery period, deaths were predominantly cardiovascular, with no specific subcategory being a leading cause of death (Table 4). In nearly $50 \%$ of patients in each group, the specific underlying cause of death could not be determined. The inciting cause of death for patients in the TAVR group who died from complications was frequently due to respiratory complications; pneumonia and aspiration were the most common causes.

In most of the deaths, hierarchical classification (Table 4) identified causes other than those directly related to the procedure or disease repair $(96.4 \%$ and $91.3 \%$ for TAVR and SAVR patients, respectively).

\section{Discharge Disposition}

Overall, patients undergoing TAVR were more frequently discharged home than SAVR patients $(85.1 \%$ vs $54.3 \%)$ (Table 5). More SAVR patients were discharged to a rehabilitation facility ( $22.2 \%$ vs $6.7 \%$ of TAVR patients).

\section{DISCUSSION}

In this intermediate-risk patient population, TAVR with the CoreValve and Evolut $\mathrm{R}$ self-expanding valves or SAVR have similar all-cause mortality during all time periods examined, including at 1 year, ${ }^{10}$ but with different inciting causes. Insights into the causes of death following cardiac surgery or intervention may help improve outcomes. Recognizing that death after cardiovascular procedures may follow a cascade of events, we applied the methodology of categorizing the inciting cause of death in a hierarchical manner as previously reported in patients from the CoreValve US Pivotal High-Risk Trial. ${ }^{7}$ Unlike the striking temporal differences in mortality risk reported in the CoreValve US Pivotal High-Risk Trial, ${ }^{7}$ the instantaneous mortality hazards in the SURTAVI trial (Figure 1) were similar for patients undergoing TAVR and SAVR, highlighting the narrowing of differences between patients undergoing these 2 different methods for replacing an aortic valve. Using our hierarchical method of categorizing the causes of mortality, the primary cause of death in the early postprocedure period for the TAVR patients was due to technical reasons and due to complications in the midterm recovery period. During the immediate postprocedure period $(<72 \text { hours })^{11}$ the number of patients who died in each group was similar (4 SAVR group deaths and 5 TAVR group deaths). The primary cause of death in SAVR patients was due to complications in the early and recovery periods, consistent with the adjudication of the CEC. The most notable finding is that the proportion of SAVR patients (30 out of 67 [44.8\%]) who died due to failure to alleviate the aortic stenosis or failure to recover seen with the CoreValve US Pivotal High-Risk Trial, ${ }^{7}$ was greatly reduced in SURTAVI (2 out of 52 [3.8\%]), highlighting the ability of this lower-risk patient group to recover from the physiological insult of surgery.

The major cause of death for SAVR patients was due to complications in the early and midterm recovery periods. Complications most frequently included AKI, AF, bleeding, and cardiogenic shock. These complications were often associated with the need for inotropic support and the final event was often multiorgan dysfunction and sepsis.

AKI was significantly higher in the TAVR patients who died early in our study and has been previously reported to be associated with higher mortality following TAV. ${ }^{12}$ Preconditioning and limiting or dilution of contrast use may offset acute procedure-related impact on kidney function. AKI has also been previously identified as an independent predictor of mortality following cardiac surgery. ${ }^{13}$

Based on our hierarchical categories, procedural technical failures were the primary cause of early mortality in the TAVR patients. Of the 11 technical deaths, 4 patients experienced left ventricle perforation, and 6 required a second valve due to malposition or paravalvular leak. Vascular complications and valve related rehospitalizations were more frequent in patients who died early. The majority $(84 \%)$ of TAVR patients in the SURTAVI trial were treated with an earlier generation CoreValve bioprosthesis. The second-generation Evolut $\mathrm{R}$ valve was added later during enrollment accounting for the remaining $16 \%$ of cases. 
TABLE 3. Clinical outcomes for patients in the transcatheter aortic valve replacement (TAVR) and surgical aortic valve replacement (SAVR) groups for patients who died and survived for the 3 time periods

\begin{tabular}{|c|c|c|c|c|c|c|c|c|c|c|c|c|}
\hline \multirow[b]{3}{*}{ Outcome } & \multicolumn{4}{|c|}{0 to $30 \mathrm{~d}$} & \multicolumn{4}{|c|}{31 to $120 \mathrm{~d}$} & \multicolumn{4}{|c|}{121 to $365 d$} \\
\hline & \multicolumn{2}{|c|}{ TAVR } & \multicolumn{2}{|c|}{ SAVR } & \multicolumn{2}{|c|}{ TAVR } & \multicolumn{2}{|c|}{ SAVR } & \multicolumn{2}{|c|}{ TAVR } & \multicolumn{2}{|c|}{ SAVR } \\
\hline & $\begin{array}{c}\text { Dead } \\
(n=18)\end{array}$ & $\begin{array}{c}\text { Alive } \\
(\mathrm{n}=846)\end{array}$ & $\begin{array}{c}\text { Dead } \\
(n=13)\end{array}$ & $\begin{array}{c}\text { Alive } \\
(\mathrm{n}=\mathbf{7 7 8})\end{array}$ & $\begin{array}{c}\text { Dead } \\
(\mathbf{n}=10)\end{array}$ & $\begin{array}{c}\text { Alive } \\
(\mathbf{n}=\mathbf{8 3 3})\end{array}$ & $\begin{array}{c}\text { Dead } \\
(n=16)\end{array}$ & $\begin{array}{c}\text { Alive } \\
(\mathbf{n}=\mathbf{7 5 3})\end{array}$ & $\begin{array}{c}\text { Dead } \\
(n=28)\end{array}$ & $\begin{array}{c}\text { Alive } \\
(\mathrm{n}=777)\end{array}$ & $\begin{array}{c}\text { Dead } \\
(\mathbf{n}=\mathbf{2 3})\end{array}$ & $\begin{array}{c}\text { Alive } \\
(n=691)\end{array}$ \\
\hline Stroke & $5(67.2)^{*}$ & $23(2.7)^{*}$ & $2(19.2)$ & $41(5.3)$ & $1(14.3)$ & $33(3.1)$ & $5(66.1)^{*}$ & $45(5.6)^{*}$ & $2(9.2)$ & $36(4.6)$ & $5(23.9) *$ & $38(5.5)^{*}$ \\
\hline Disabling & $4(45.3)^{*}$ & $6(0.7)^{*}$ & $2(19.2)^{*}$ & $17(2.2)^{*}$ & $1(14.3)^{*}$ & $9(0.8)^{*}$ & $4(62.5)^{*}$ & $19(2.1)^{*}$ & $2(9.2)^{*}$ & $11(1.4)^{*}$ & $5(23.9) *$ & $14(2.0)^{*}$ \\
\hline $\begin{array}{l}\text { Atrial } \\
\quad \text { fibrillation } \dagger\end{array}$ & $4(41.3)^{*}$ & $105(12.4)^{*}$ & $6(58.3)$ & $334(42.9)$ & $0(0.0)$ & $133(14.9)$ & $12(76.6)^{*}$ & $330(43.4)^{*}$ & $8(32.0)$ & 135 (17.4) & $11(71.7)$ & $310(44.9)$ \\
\hline Reintervention & $1(7.1)^{*}$ & $6(0.7)^{*}$ & $0(0.0)$ & $1(0.1)$ & $0(0.0)$ & $14(1.3)$ & $2(16.7)^{*}$ & $0(0.0)^{*}$ & $1(6.7)$ & $15(1.9)$ & $0(0.0)$ & $1(0.1)$ \\
\hline Major bleed & $0(0.0)$ & $58(6.9)$ & $0(0.0)$ & $27(3.5)$ & $0(0.0)$ & $72(8.2)$ & $3(18.8)^{*}$ & $36(4.1)^{*}$ & $6(22.2)^{*}$ & $73(9.4)^{*}$ & $2(10.0)$ & $38(5.5)$ \\
\hline LTDB & $12(100)^{*}$ & $37(4.4)^{*}$ & $3(23.1)^{*}$ & $44(5.7)^{*}$ & $1(10.0)$ & $44(4.9)$ & $5(100)^{*}$ & $48(5.8)^{*}$ & $3(12.9)$ & $46(5.9)$ & $3(27.0)$ & $45(6.5)$ \\
\hline $\begin{array}{c}\text { Transfusion } \\
>1 \mathrm{U}_{\ddagger}^{\dagger}\end{array}$ & $12(66.7)^{*}$ & $109(12.9)^{*}$ & $10(76.9)$ & $371(47.7)$ & $2(20.0)$ & $106(12.7)$ & $11(68.8)$ & $355(47.1)$ & $9(32.1)^{*}$ & $93(12.0)^{*}$ & $16(69.6)^{*}$ & $322(46.6) *$ \\
\hline $\begin{array}{l}\text { Major vascular } \\
\text { complication }\end{array}$ & $7(39.4)^{*}$ & $44(5.2)^{*}$ & $1(7.7)^{*}$ & $8(1.0)^{*}$ & $2(32.5)^{*}$ & $45(5.3)^{*}$ & $0(0.0)$ & $8(1.1)$ & $3(10.7)$ & $40(5.1)$ & $0(0.0)$ & $7(1.0)$ \\
\hline AKI & $8(61.0)^{*}$ & $40(4.7)^{*}$ & $6(48.1)^{*}$ & $121(15.6)^{*}$ & $1(10.0)$ & $40(4.7)$ & $6(37.5)^{*}$ & $114(15.1)^{*}$ & $2(7.1)$ & $36(4.6)$ & $6(26.1)$ & 101 (14.6) \\
\hline MI & $3(25.3) *$ & $4(0.5) *$ & $2(15.4) *$ & $5(0.6)^{*}$ & $1(10.0) *$ & $6(0.7) *$ & $2(12.5) *$ & $7(0.8)^{*}$ & $2(8.4)^{*}$ & $10(1.3)^{*}$ & $0(0.0)$ & $6(0.9)$ \\
\hline $\begin{array}{l}\text { Cardiac } \\
\quad \text { perforation }\end{array}$ & $6(33.3)^{*}$ & $8(0.9) *$ & $1(7.7)^{*}$ & $5(0.6)^{*}$ & $0(0.0)$ & $8(1.0)$ & $0(0.0)$ & $5(0.7)$ & $0(0.0)$ & $8(1.0)$ & $0(0.0)$ & $5(0.7)$ \\
\hline $\begin{array}{l}\text { Cardiac } \\
\quad \text { tamponade }\end{array}$ & $5(27.8)^{*}$ & $7(0.8)^{*}$ & $1(7.7)^{*}$ & $9(1.2)^{*}$ & $0(0.0)$ & $8(1.0)$ & $1(6.3)$ & $9(1.2)$ & $0(0.0)$ & $8(1.0)$ & $2(8.7)^{*}$ & $7(1.0)^{*}$ \\
\hline Endocarditis & $0(0.0)$ & $0(0.0)$ & $0(0.0)$ & $0(0.0)$ & $0(0.0)$ & $1(0.1)$ & $1(7.7)^{*}$ & $2(0.1)^{*}$ & $0(0.0)$ & $2(0.3)$ & $2(28.8) *$ & $1(0.1)^{*}$ \\
\hline Valve thrombosis & $0(0.0)$ & $1(0.1)$ & $0(0.0)$ & $0(0.0)$ & $0(0.0)$ & $1(0.1)$ & $0(0.0)$ & $0(0.0)$ & $0(0.0)$ & $2(0.3)$ & $0(0.0)$ & $0(0.0)$ \\
\hline $\begin{array}{l}\mathrm{AV} \\
\quad \text { hospitalization }\end{array}$ & $0(0.0)$ & $24(2.8)$ & $0(0.0)$ & $32(4.1)$ & $2(40.0)^{*}$ & $54(5.8)^{*}$ & $2(12.5)$ & $43(5.6)$ & $11(50.5)^{*}$ & $57(7.3)^{*}$ & $3(25.5)$ & $48(6.9)$ \\
\hline $\mathrm{PPI} \S$ & $2(14.9)$ & $218(25.8)$ & $1(14.3)$ & $50(6.4)$ & $1(10.0)$ & $230(27.1)$ & $2(12.5)$ & $55(6.9)$ & $8(28.6)$ & $224(28.8)$ & $2(8.7)$ & $58(8.4)$ \\
\hline $\begin{array}{c}\text { Coronary artery } \\
\text { obstruction }\end{array}$ & $1(5.6)^{*}$ & $1(0.1)^{*}$ & $0(0.0)$ & $0(0.0)$ & $0(0.0)$ & $1(0.1)$ & $0(0.0)$ & $0(0.0)$ & $0(0.0)$ & $1(0.1)$ & $0(0.0)$ & $0(0.0)$ \\
\hline $\begin{array}{l}\text { Procedural } \\
\text { conversion }\end{array}$ & $4(23.6)^{*}$ & $7(0.8)^{*}$ & $1(7.7)^{*}$ & $1(0.1)^{*}$ & $1(10.0)^{*}$ & $6(0.7)^{*}$ & $0(0.0)$ & $1(0.1)$ & $1(3.6)$ & $5(0.6)$ & $0(0.0)$ & $1(0.1)$ \\
\hline To open surgery & $3(17.9)^{*}$ & $4(0.5)^{*}$ & $0(0.0)$ & $0(0.0)$ & $0(0.0)$ & $4(0.5)$ & $0(0.0)$ & $0(0.0)$ & $1(3.6)$ & $3(0.4)$ & $0(0.0)$ & $0(0.0)$ \\
\hline $\begin{array}{l}\text { TAVR to other } \\
\text { percutaneous }\end{array}$ & $0(0.0)$ & $1(0.1)$ & $0(0.0)$ & $0(0.0)$ & $0(0.0)$ & $1(0.1)$ & $0(0.0)$ & $0(0.0)$ & $0(0.0)$ & $1(0.1)$ & $0(0.0)$ & $0(0.0)$ \\
\hline $\begin{array}{l}\text { SAVR to } \\
\text { alternative } \\
\text { procedure }\end{array}$ & $0(0.0)$ & $0(0.0)$ & $1(7.7)^{*}$ & $0(0.0)^{*}$ & $0(0.0)$ & $0(0.0)$ & $0(0.0)$ & $0(0.0)$ & $0(0.0)$ & $0(0.0)$ & $0(0.0)$ & $0(0.0)$ \\
\hline Aborted procedure & $1(5.6)^{*}$ & $2(0.2) *$ & $0(0.0)$ & $1(0.1)$ & $0(0.0)$ & $0(0.0)$ & $0(0.0)$ & $1(0.1)$ & $0(0.0)$ & $1(0.1)$ & $0(0.0)$ & $1(0.1)$ \\
\hline
\end{tabular}

Values are presented as mean \pm standard deviation or number of patients with an event (Kaplan-Meier rates as percentage). TAVR, Transcatheter aortic valve replacement; $S A V R$, surgical aortic valve replacement; $L T D B$, life-threatening or disabling bleeding; $A K I$, acute kidney injury; $M I$, myocardial infarction; $A V$, aortic valve; $P P I$, permanent pacemaker implantation. ${ }^{*} P<.05$ for dead versus alive. $†$ New or worsening atrial fibrillation not adjudicated by the Clinical Events Committee. $\ddagger$ Any homologous blood product. $§$ Including patients with a pacemaker at baseline.

This newer generation valve has a lower vascular profile (ie, can be implanted in vessels $\geq 5 \mathrm{~mm} \mathrm{[} \geq 5.5 \mathrm{~mm}$ with the 34 $\mathrm{mm}$ valve] vs $\geq 6 \mathrm{~mm}$ with the CoreValve bioprosthesis), can be partially or fully recaptured to assist with valve positioning and has shown low mortality rates in high and extreme-risk patients of $8.6 \%$ at 1 year, and lower rates of moderate or severe paravalvular leak. ${ }^{14,15}$ The ability to reposition the Evolut $\mathrm{R}$ valve may allow more precise positioning and reduce the need for a second valve.
Stroke following either TAVR or SAVR is associated with higher mortality ${ }^{16}$ which we also found in our study.

The influence of AF on SAVR- and TAVR-related mortality is complex, due to cardioembolic risks associated with $\mathrm{AF}$ as well as potential bleeding complications related to antithrombotic therapy. Randomized AVR trials have shown new-onset AF occurs more often after SAVR than after TAVR. ${ }^{2,5,6}$ The presence of AF at baseline was more common in patients undergoing SAVR. ${ }^{6}$ 
TABLE 4. Clinical Events Committee (CEC) adjudication and hierarchical classification of deaths per follow-up period

\begin{tabular}{|c|c|c|c|c|c|c|}
\hline & \multicolumn{2}{|c|}{0 to $30 \mathrm{~d}$} & \multicolumn{2}{|c|}{31 to $120 \mathrm{~d}$} & \multicolumn{2}{|c|}{121 to $365 d$} \\
\hline & $\begin{array}{c}\text { TAVR } \\
(n=864)\end{array}$ & $\begin{array}{c}\text { SAVR } \\
(n=796)\end{array}$ & $\begin{array}{c}\text { TAVR } \\
(n=846)\end{array}$ & $\begin{array}{c}\text { SAVR } \\
(n=778)\end{array}$ & $\begin{array}{c}\text { TAVR } \\
(n=833)\end{array}$ & $\begin{array}{c}\text { SAVR } \\
(n=753)\end{array}$ \\
\hline No. of deaths & 18 & 13 & 10 & 16 & 28 & 23 \\
\hline \multicolumn{7}{|l|}{ CEC adjudication } \\
\hline Cardiovascular & $17(94.4)$ & $13(100)$ & $7(70.0)$ & $12(75.0)$ & $16(57.1)$ & $16(69.6)$ \\
\hline Valve-related & 0 & 0 & 0 & $1(6.3)$ & 0 & 0 \\
\hline Complications of the procedure & $11(61.1)$ & $5(38.5)$ & $2(20.0)$ & $3(18.8)$ & 0 & 0 \\
\hline Sudden/unwitnessed & $1(5.6)$ & 0 & $1(10.0)$ & $3(18.8)$ & $2(7.1)$ & $1(4.3)$ \\
\hline Worsening heart failure & 0 & 0 & $1(10.0)$ & $2(12.5)$ & $3(10.7)$ & $1(4.3)$ \\
\hline Myocardial infarction & $1(5.6)$ & $1(7.7)$ & 0 & 0 & $1(3.6)$ & 0 \\
\hline Arrhythmia & 0 & $1(7.7)$ & 0 & 0 & 0 & $1(4.3)$ \\
\hline Cardiac tamponade & $1(5.6)$ & 0 & 0 & 0 & 0 & 0 \\
\hline Neurological event & $2(11.1)$ & $1(7.7)$ & $1(10.0)$ & $2(12.5)$ & $2(7.1)$ & $2(8.7)$ \\
\hline Other vascular disease & $1(5.6)$ & 0 & 0 & 0 & 0 & $1(4.3)$ \\
\hline Other & 0 & $2(15.4)$ & $1(10.0)$ & 0 & 0 & $2(8.7)$ \\
\hline Unknown & 0 & $3(23.1)$ & $1(10.0)$ & $1(6.3)$ & $8(28.6)$ & $8(34.8)$ \\
\hline Noncardiovascular & $1(5.6)$ & 0 & $3(30.0)$ & $4(25.0)$ & $12(42.9)$ & $7(30.4)$ \\
\hline Malignancy & 0 & 0 & 0 & $2(12.5)$ & 0 & $1(4.3)$ \\
\hline Accidental & 0 & 0 & 0 & 0 & $2(7.1)$ & 0 \\
\hline Infection/sepsis & $1(5.6)$ & 0 & $3(30.0)$ & 0 & $5(17.9)$ & $5(21.7)$ \\
\hline Renal disease & 0 & 0 & 0 & 0 & $2(7.1)$ & 0 \\
\hline COPD & 0 & 0 & 0 & 0 & 0 & $1(4.3)$ \\
\hline Other & 0 & 0 & 0 & $2(12.5)$ & $3(10.7)$ & 0 \\
\hline \multicolumn{7}{|l|}{ Hierarchical classification } \\
\hline Technical & $11(61.1)$ & $2(15.4)$ & $1(10.0)$ & $2(12.5)$ & 0 & 0 \\
\hline Failure to repair & $1(5.6)$ & 0 & 0 & 0 & $1(2.7)$ & 0 \\
\hline Complications & $6(33.3)$ & $11(84.6)$ & $9(90.0)$ & $7(43.8)$ & 0 & $1(4.3)$ \\
\hline Failure to recover & 0 & 0 & 0 & $1(6.3)$ & 0 & $1(4.3)$ \\
\hline Other & 0 & 0 & 0 & $6(37.5)$ & $27(97.3)$ & $21(91.3)$ \\
\hline
\end{tabular}

Values are presented as n (\%). TAVR, Transcatheter aortic valve replacement; $S A V R$, surgical aortic valve replacement; $C E C$, Clinical Events Committee; $C O P D$, chronic obstructive pulmonary disease.

In our study, the incidence of baseline AF did not differ between those who died and survivors, but patients who died early had a higher incidence of AF documented. Baseline and new-onset AF have been associated with increased mortality. ${ }^{17}$

Bleeding events differ between patients undergoing SAVR and TAVR, because TAVR patients experience bleeding events often associated with vascular complications ${ }^{18,19}$ which has been associated with higher risk of 30-day and 1-year mortality. ${ }^{19}$ Within the TAVR group, transfusions in the early period were significantly higher in those who died. The reason for the transfusion in the early period for TAVR is usually related to a procedure complication such as vascular injury or ventricular perforation. For SAVR patients in the early period, the need for transfusion was higher than for TAVR patients during this period. Major bleeding within 30-days postprocedure was a positive predictor of 1-year mortality following TAVR. ${ }^{20}$ Reducing early vascular complications and bleeding in TAVR may have positive longer-term consequences.
After 120 days, most of the deaths in both groups were categorized as other using our system, and were likely related more to the patients underlying comorbid condition, than the procedural insult.

Patient prosthetic mismatch (PPM) has previously been studied, ${ }^{21}$ with severe mismatch more common in surgery patients. Severe mismatch was associated with increased mortality at 1 year for TAVR and SAVR in that study of high-risk patients. ${ }^{21}$ For our intermediate-risk study, severe PPM was more common in surgery than TAVR but did not influence early or 1-year survival. A manuscript with a more detailed analysis of PPM in this trial is under review.

Although the failure to recover from the procedure was an important driver for mortality in high-risk SAVR patients, ${ }^{7}$ this was not the case in this intermediate-risk cohort with complications shown to be a major cause of death, especially during the early and recovery phases. This likely reflects this group's lower risk and ability to withstand and recover from the physiologic insult of surgery. In SURTAVI, more patients in both groups were discharged home 
TABLE 5. Discharge location

\begin{tabular}{lccc}
\hline & $\begin{array}{c}\text { TAVR } \\
(\mathbf{n}=\mathbf{8 3 0})\end{array}$ & $\begin{array}{c}\text { SAVR } \\
(\mathbf{n}=\mathbf{6 8 8})\end{array}$ & $\boldsymbol{P}$ value \\
\hline Discharge location & & & $<.001$ \\
Died in hospital & $13(1.5)$ & $11(1.4)$ & \\
Home & $735(85.1)$ & $432(54.3)$ & \\
Rehabilitation clinic & $58(6.7)$ & $177(22.2)$ & \\
Skilled nursing facility & $34(3.9)$ & $106(13.3)$ & \\
Another hospital & $11(1.3)$ & $29(3.6)$ & \\
Other & $13(1.5)$ & $41(5.2)$ & \\
\hline
\end{tabular}

Values are presented as $\mathrm{n}(\%)$

than in the CoreValve US Pivotal High-Risk Trial. ${ }^{7}$ Whereas nearly all TAVR patients were discharged home, about $50 \%$ of SAVR patients were discharged to a stepdown facility.

Overall, our results suggest that prevention of technical, procedure-related complications during TAVR may further reduce the incidence of fatal outcome during the early postprocedural period while reducing complications may further improve early survival after SAVR and overall survival for both TAVR and SAVR.

\section{Limitations}

This post hoc analysis was performed on data obtained from the SURTAVI trial, in which the CoreValve and Evolut $\mathrm{R}$ bioprostheses were implanted. We did not use any adjustments for multiple comparisons in our analyses. The number of events in each group is small and we acknowledge that any statistical comparisons should be considered in this regard. Valve-specific effects cannot be excluded; therefore, outcomes cannot be extrapolated to other selfexpanding or balloon-expandable devices. We did not have details of medication use to aid in the determination of the hierarchical causes.

The analysis addressed all-cause mortality at 1-year postprocedure in patients at intermediate risk for surgery. As

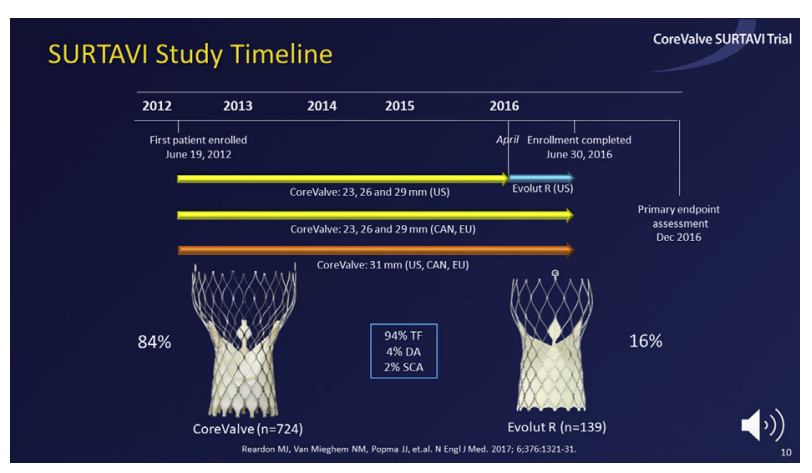

VIDEO 1. Recorded presentation from the American Association for Thoracic Surgery Conference May 1, 2018. Video available at: https:// www.jtcvs.org/article/S0022-5223(18)33290-2/fulltext. such patients may be of younger age than typical highrisk patients, longer-term follow-up is particularly important for this population and warrants further research. Other aspects not explicitly assessed in this analysis may influence longer-term survival after TAVR and SAVR, such as PPM and paravalvular leak. These phenomena may have different incidences and develop differently at longer-term in TAVR versus SAVR patients.

\section{CONCLUSIONS}

All-cause mortality at 1 year was similar for intermediate-risk patients undergoing TAVR or SAVR, with no differences in mortality during the early, recover, or late time periods. The primary cause of early death in the TAVR patients was related to the procedure, and in the SAVR patients, the primary cause of early death was postoperative complications. The greatest opportunity for decreasing mortality for both TAVR and SAVR is in the procedural period, when the greatest instantaneous risk of death occurred. There is a potential for further reduction of all-cause mortality after TAVR by prevention of technical, procedure-related problems. Further reduction of complications may improve survival of intermediate-risk patients after SAVR and TAVR.

\section{Webcast}

You can watch a Webcast of this AATS meeting presentation by going to: https://aats.blob.core.windows.net/ media/18May01/20ABC\%202.TCT/S92_1.mp4.

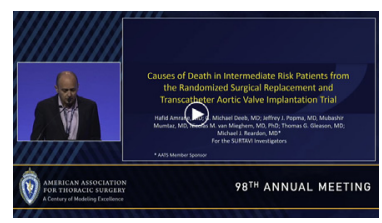

\section{Conflict of Interest Statement}

Dr Amrane serves as a consultant to Abbott and has received research grants from Medtronic and Abbott. Dr Deeb serves as on an advisory board and as a proctor for Medtronic, as a consultant and research investigator for Edwards Lifesciences, as a consultant and proctor for Terumo, and as a research investigator for Gore Medical. He receives no personal remunerations. Dr Williams serves as a consultant for Edwards Lifesciences and Medtronic, as a speaker for Abbott Laboratories, and has received research grants from Medtronic. Dr Popma has received institutional research grants from Medtronic, Boston Scientific, and Direct Flow Medical, and has served on a Medical Advisory Board for Boston Scientific, Cordis Corporation, and Edwards Lifesciences. Dr Mumtaz has served as a proctor, served as a consultant, and received honoraria, consulting fees, and travel reimbursements from Medtronic, Abbott, 
Edwards Lifesciences, and Atricure. Dr Kappetein is an employee of Medtronic. Dr Yakubov has received institutional research grants from Boston Scientific, Direct Flow, and Medtronic. Dr Van Mieghem has received grant support from Abbott Vascular, Boston Scientific, Claret Medical, and Medtronic. Dr Gleason receives institutional grant support from Medtronic but receives no personal income. Dr Serruys receives personal fees from Abbott Laboratories, AstraZeneca, Biotronik, Cardialysis, GLG research, Medtronic, Sino Medical Sciences Technology, and Societe Europa Digital Publishing, Stentys Fran, Svellte Medical Systems, Philips/Volcano, St Jude Medical and Qualimed. Dr Tadros discloses a financial relationship with Medtronic and St. Jude Medical. Dr Zorn has a financial relationship with Medtronic and Edwards Lifesciences. $\mathrm{Dr} \mathrm{Li}$ is an employee and shareholder of Medtronic. Dr Reardon has received fees from Medtronic for providing educational services. All other authors have nothing to disclose with regard to commercial support.

Jane Moore, MS, ELS, an employee of the sponsor, created all figures and tables, and drafted the introduction, methods, and results sections under the direction of Drs Amrane and Reardon, and ensured the technical accuracy of the information presented.

Members of the SURTAVI Trial Causes of Death Working Group include Mathew R. Williams, MD (New York UniversityLangone Medical Center, New York, NY); Mubashir Mumtaz, MD (University of Pittsburg Medical Center Pinnacle, Wormsleyburg, Pa); Arie Pieter Kappetein, MD, PhD (Erasmus Medical Center, Rotterdam, the Netherlands); Patrick W. Serruys, MD, $\mathrm{PhD}$ (International Centre for Circulatory Health, National Heart Lung Institute, Imperial College London, London, United Kingdom); Peter Tadros, MD, and George L. Zorn III, MD (University of Kansas, Kansas City, Kan); Piet W. Boonstra, MD, and Ad van Boven, MD (Medisch Centrum Leeuwarden, the Netherlands); and Shuzhen Li, PhD (Statistical Services, Medtronic, Minneapolis, Minn).

\section{References}

1. Cribier A, Eltchaninoff H, Bash A, Borenstein N, Tron C, Bauer F, et al. Percutaneous transcatheter implantation of an aortic valve prosthesis for calcific aortic stenosis: first human case description. Circulation. 2002;106:3006-8.

2. Adams DH, Popma JJ, Reardon MJ, Yakubov SJ, Coselli JS, Deeb GM, et al. Transcatheter aortic-valve replacement with a self-expanding prosthesis. $N$ Engl J Med. 2014;370:1790-8.

3. Leon MB, Smith CR, Mack M, Miller DC, Moses JW, Svensson LG, et al. Transcatheter aortic-valve implantation for aortic stenosis in patients who cannot undergo surgery. N Engl J Med. 2010;363:1597-607.

4. Popma JJ, Adams DH, Reardon MJ, Yakubov SJ, Kleiman NS, Heimansohn D, et al. Transcatheter aortic valve replacement using a self-expanding bioprosthesis in patients with severe aortic stenosis at extreme risk for surgery. J Am Coll Cardiol. 2014;63:1972-81.

5. Leon MB, Smith CR, Mack MJ, Makkar RR, Svensson LG, Kodali SK, et al. Transcatheter or surgical aortic-valve replacement in intermediate-risk patients. N Engl J Med. 2016:374:1609-20.
6. Reardon MJ, Van Mieghem NM, Popma JJ, Kleiman MS, Sondergaard L, Mumtaz M, et al. Surgical or transcatheter aortic-valve replacement in intermediate-risk patients. New Engl J Med. 2017;376:1321-31.

7. Gaudiani V, Deeb GM, Popma JJ, Adams DH, Gleason TG, Conte JV, et al. Causes of death from the randomized CoreValve US pivotal high-risk trial. $J$ Thorac Cardiovasc Surg. 2017;153:1293-12301.e1.

8. Database SACS. Executive summary. Available at: https://www.sts.org/sites/ default/files/documents/ACSD2017Harvest3_ExecutiveSummary.pdf.

9. Eggebrecht H, Mehta RH. Transcatheter aortic valve implantation (TAVI) in Germany 2008-2014: on its way to standard therapy for aortic valve stenosis in the elderly? EuroIntervention. 2016;11:1029-33.

10. Van Mieghem N, Reardon MJ, Popma JJ, Windecker S, Gleason T, LEe J, et al Transcatheter aortic valve replacement with a self-expanding prosthesis or surgical aortic valve replacement in intermediate-risk patients: complete 1-year outcome from the SURTAVI trial [abstract TCT-107]. J Am Coll Cardiol. 2017;70:B47.

11. Kappetein AP, Head SJ, Genereux P, Piazza N, van Mieghem NM, Blackstone EH, et al. Updated standardized endpoint definitions for transcatheter aortic valve implantation: the valve academic research consortium2 consensus document (VARC-2). Eur J Cardiothorac Surg. 2012;42: S45-60.

12. Arsalan M, Squiers JJ, Farkas R, Worley C, Herbert M, Stewart W, et al. Prognostic usefulness of acute kidney injury after transcatheter aortic valve replacement. Am J Cardiol. 2016;117:1327-31.

13. Kandler K, Jensen ME, Nilsson JC, Moller CH, Steinbruchel DA. Acute kidney injury is independently associated with higher mortality after cardiac surgery. $J$ Cardiothorac Vasc Anesth. 2014;28:1448-52.

14. Popma JJ, Reardon MJ, Khabbaz K, Harrison JK, Hughes GC, Kodali S, et al. Early clinical outcomes after transcatheter aortic valve replacement using a novel self-expanding bioprosthesis in patients with severe aortic stenosis who are suboptimal for surgery: results of the Evolut R U.S. study. J Am Coll Cardiol Intv. 2017:10:268-75.

15. Popma JJ, Hughes GC, Kodali S, George I, Oh JK, Slater J, et al. Transcatheter aortic valve replacement with a repositionable self-expanding bioprosthesis in patients with severe aortic stenosis at high risk for surgery: one-year results from the Evolut R US pivotal study [abstract TCT-37]. J Am Coll Cardiol. 2016;68:B16.

16. Gleason TG, Schindler JT, Adams DH, Reardon MJ, Kleiman NS, Caplan LR, et al. The risk and extent of neurologic events are equivalent for high-risk patients treated with transcatheter or surgical aortic valve replacement. J Thorac Cardiovasc Surg. 2016;152:85-96.

17. Tarantini G, Mojoli M, Windecker S, Wendler O, Lefevre T, Saia F, et al. Prev alence and impact of atrial fibrillation in patients with severe aortic stenosis undergoing transcatheter aortic valve replacement: an analysis from the SOURCE XT prospective multicenter registry. JACC Cardiovasc Interv. 2016;9:937-46.

18. Conte JV, Hermiller J Jr, Resar JR, Deeb GM, Gleason TG, Adams DH, et al Complications after self-expanding transcatheter or surgical aortic valve replacement. Semin Thorac Cardiovasc Surg. 2017;29:321-30.

19. Genereux P, Webb JG, Svensson LG, Kodali SK, Satler LF, Fearon WF, et al. Vascular complications after transcatheter aortic valve replacement: insights from the PARTNER (Placement of AoRTic TraNscathetER Valve) trial. J Am Coll Cardiol. 2012;60:1043-52.

20. Généreux P, Cohen DJ, Williams MR, Mack M, Kodali SK, Svensson LG, et al. Bleeding complications after surgical aortic valve replacement compared with transcatheter aortic valve replacement: insights from the PARTNER I trial (Placement of Aortic Transcatheter Valve). J Am Coll Cardiol. 2014;63:1100-9.

21. Zorn GL III, Little SH, Tadros P, Deeb GM, Gleason TG, Heiser J, et al. Prosthesis-patient mismatch in high-risk patients with severe aortic stenosis: a randomized trial of a self-expanding prosthesis. J Thorac Cardiovasc Surg. 2016; 151:1014-23.e3.

Key Words: transcatheter aortic valve replacement, surgical aortic valve replacement, intermediate risk, causes of death 
Discussion

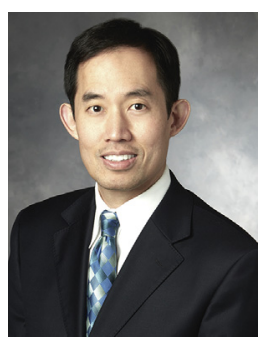

Dr Y. Joseph Woo (Stanford, Calif). I congratulate Drs Amrane and Reardon and the authors on this multi-institutional, post hoc analysis of the Surgical Replacement and Transcatheter Aortic Valve Implantation randomized prospective controlled trial of self-expanding transcatheter aortic valve replacement (TAVR) for aortic stenosis in intermediaterisk patients, Society of Thoracic Surgeons predicted risk of mortality $3 \%$ to $15 \%$ (mean, $4.5 \%$ ). The study assigns cause of death into 5 categories during 3 postprocedure periods. The categories, arguably potentially overlapping, are Technical, Failed repair of aortic stenosis, Complications, Failure to recover, and Other. The time periods are very definitive, essentially 1 month, 4 months, and 1 year. The predominant finding that TAVR and surgical aortic valve replacement (SAVR) all-cause mortality were equivalent but more related to technical challenges in TAVR and more related to-early and recovery period postoperative complications in SAVR are not very surprising. The delineation is valuable.

I have 4 areas of inquiry. First, let us explore coronary revascularization. In your research you detected a significant 2-fold increase in need for revascularization among patients undergoing TAVR who ultimately died. Was revascularization primarily for known coronary disease or a response to implantation issues with obstruction, and if the former, are you willing to contend that patients with AS and coronary disease are better served with SAVR plus coronary artery bypass grafting $(\mathrm{CABG}) /$ percutaneous coronary intervention?

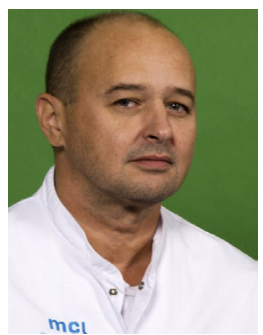

Dr Hafid Amrane (Leeuwarden, The Netherlands). What I know about this specific inquiry is that was there was an increased mortality with patients undergoing TAVR who either underwent percutaneous coronary intervention with the TAVR procedure or at another time period. I did not really have the details on the CABG group actually. What I do know is that there were about 170 patients who also underwent $\mathrm{CABG}$, and there was, according to my knowledge, no difference in survival of the people undergoing CABG.

Dr Woo. Thank you. Second. Are there any substantive differences when comparing outcomes based on intentionto-treat versus as-treated?

Dr Amrane. That's a difficult question. Could you repeat it 1 more time?

Dr Woo. Are there any differences when you look at the groups as intention-to-treat versus the as-treated?
Dr Amrane. In the Surgical Replacement and Transcatheter Aortic Valve Implantation study we didn't call it astreated but modified intention-to-treat. There were some differences. I think the group we called modified intention-to-treat were patients who had an attempted implant. So there was some difference between those 2 groups, although not very substantive.

Dr Woo. Third. Let us speculate on the attenuation of technical challenges during TAVR. What device-related or implantation technique-related advancements might have the greatest influence on mitigating this category?

Dr Amrane. Yes, a good question. As you have seen in the periprocedural phase, there was quite a high percentage of technical failures. Now, these were left ventricular perforation and use of multiple valves, usually 2 valves, because during the procedure the valve prolapsed or it was misplaced. But actually the incidence of these failures and potential disasters, as we have seen, should have fallen to a very low percentage because these procedures happened at a time when there were no preshaped wires and mostly were done with the first-generation CoreValve (Medtronic, Minneapolis, Minn). So I think if you do the same trial today, your periprocedural mortality for TAVR would be considerably diminished.

Dr Woo. Great. Finally, given that insightful answer to the last question, let us engender some controversy. Technologic evolution is inevitable and presumably ultralow-profile, nonvascular injury devices guided by perfectly precise imaging modalities are within reach. What will be the role of cardiovascular surgeons in TAVR in the future? Are we needed for TAVR or will TAVR simply become another structural heart intervention like Amplatz or atrial septal defect closure, MitraClip (Abbott Laboratories, Abbott Park, Ill), or a Melody (Medtronic) pulmonary valve replacement, and we are superfluous but for the extremely rare disaster?

Dr Amrane. Well, I'm a surgeon and I hate to say it, but I think you have a point there. If we look at the ongoing lowrisk trials, we already know that mortality is going to $0 \%$ after 30 days and with also a very low percentage of stroke. So we really have to sit back and think how we can improve our surgery, and because complications are factor number 1 in death after surgery, we should look - to get those numbers better-to atrial fibrillation, acute kidney injury, and transfusion. I think, even in treating these diseases better, it would be very difficult to score better.

So, yes, to answer your question, I think we are heading for a period where either we get involved as surgeons in TAVI as I do in my center, and yes, we will always be necessary, be it for the concomitant procedures, be it for the younger patients, be it for the endocarditis, or bicuspid valves. But I think there will come an era where the amount of surgical single heart valve procedures will drop to a pretty low level. 
Dr Woo. So that's a great answer for how to improve SAVR in that there will always be a role for the surgeon in SAVR, but what is the role of the surgeon in TAVR in the future?

Dr Amrane. Okay. In our heart center in the Netherlands, I'm the first surgeon who is actually actively involved in TAVR, and I have done a lot of transaortic cases. In the beginning it was something like $30 \%$ full surgical TAVR, but that went down to $5 \%$ to $10 \%$. In the meantime, I developed wire skills so nowadays I contribute to transfemoral cases as well and if you see what's coming our way, that it is very important for a surgeon to have these wire skills. So in terms of the future, I think we should train our residents to develop catheter and wire skills to work along with the cardiologists because there will always be disasters and there will always be situations where an acute operation is necessary to save a patient's life.

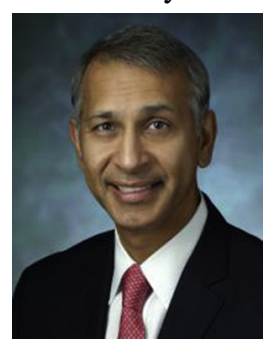

Dr Vinod H. Thourani (Washington, DC). Can I just make 1 comment? This is more of a question than it is a comment. I'm not sure what the role is going to be for TAVR in the procedure, quite honestly. We will just have to wait and see how that comes out for the first surgeons.
I have a different question. A great presentation. But when you look at the 1-year plots, there was a lot of TAVR mortality there and the categorization was Other, which the article should describe what that mortality was. So in the gray bar graph that you had, it just said "Other," and I'm not sure what that means, because the hope was that at 1 year why do patients die, what was the rationale for them to die, and having a blank and open as Other and we don't know what that means I think is a little bit underwhelming, quite honestly. Is it that the data weren't there? But what is that Other category? That was almost all the patients, $>90 \%$, at the 1-year mark.

Dr Amrane. After the periprocedural and recovery periods where you could say, okay, the injury after the procedure is now behind us, people just fall back to baseline and they get things like malignancy, they get an infection, they get another disease, another operation, or an accident. We even saw suicide. As we went through all these narratives, we really couldn't connect it to the procedure, so I guess it has to do with their comorbidity or their age or their bad luck.

Dr Thourani. Thank you very much.

Dr Woo. I commend you on your presentation and the excellent work from your group. 


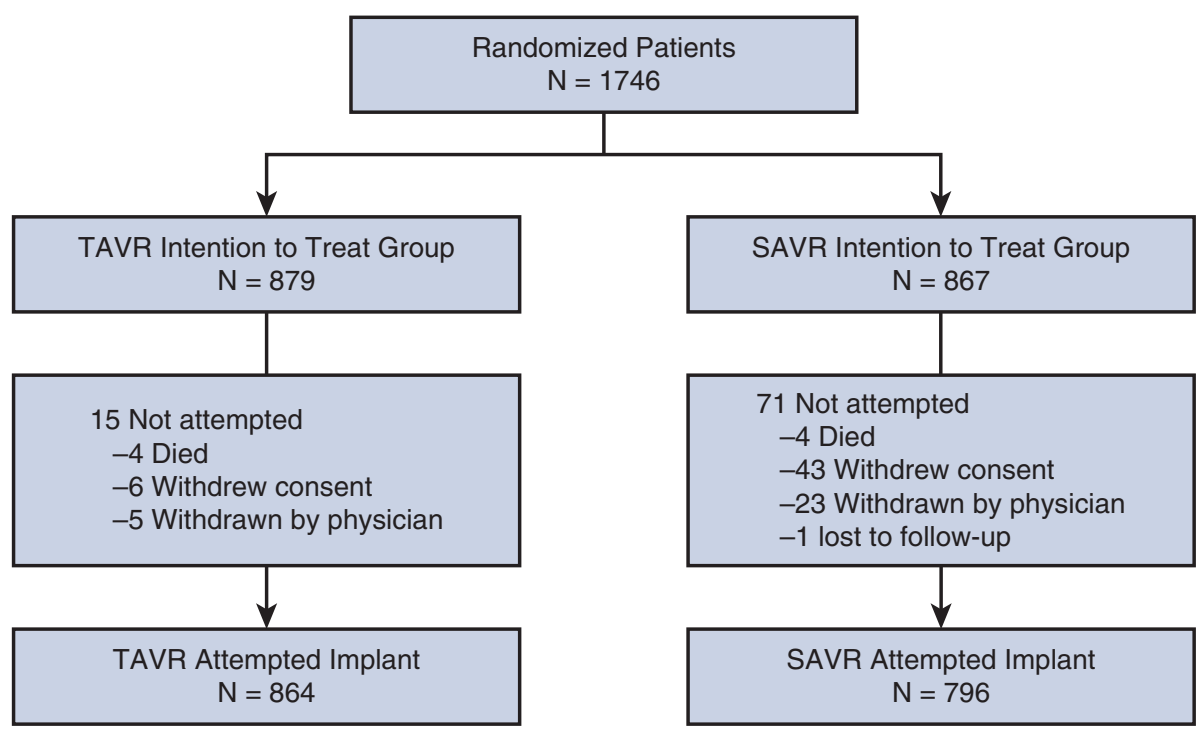

FIGURE E1. TAVR, Transcatheter aortic valve replacement; $S A V R$, surgical aortic valve replacement. 


\begin{tabular}{|c|c|c|c|c|c|c|c|c|c|c|c|c|}
\hline & \multicolumn{4}{|c|}{0 to $30 \mathrm{~d}$} & \multicolumn{4}{|c|}{31 to $120 \mathrm{~d}$} & \multicolumn{4}{|c|}{121 to $365 \mathrm{~d}$} \\
\hline & \multicolumn{2}{|c|}{ TAVR } & \multicolumn{2}{|c|}{ SAVR } & \multicolumn{2}{|c|}{ TAVR } & \multicolumn{2}{|c|}{ SAVR } & \multicolumn{2}{|c|}{ TAVR } & \multicolumn{2}{|c|}{ SAVR } \\
\hline & $\begin{array}{c}\text { Dead } \\
(\mathbf{n}=18)\end{array}$ & $\begin{array}{c}\text { Alive } \\
(n=846)\end{array}$ & $\begin{array}{c}\text { Dead } \\
(\mathbf{n}=13)\end{array}$ & $\begin{array}{c}\text { Alive } \\
(\mathrm{n}=778)\end{array}$ & $\begin{array}{c}\text { Dead } \\
(\mathbf{n}=10)\end{array}$ & $\begin{array}{c}\text { Alive } \\
(\mathrm{n}=\mathbf{8 3 3})\end{array}$ & $\begin{array}{c}\text { Dead } \\
(\mathrm{n}=16)\end{array}$ & $\begin{array}{c}\text { Alive } \\
(\mathbf{n}=\mathbf{7 5 3})\end{array}$ & $\begin{array}{c}\text { Dead } \\
(\mathrm{n}=\mathbf{2 8})\end{array}$ & $\begin{array}{c}\text { Alive } \\
(\mathbf{n}=777)\end{array}$ & $\begin{array}{c}\text { Dead } \\
(\mathbf{n}=\mathbf{2 3})\end{array}$ & $\begin{array}{c}\text { Alive } \\
(\mathrm{n}=691)\end{array}$ \\
\hline Age (y) & $79.7 \pm 7.6$ & $79.9 \pm 6.2$ & $81.0 \pm 3.5$ & $79.7 \pm 6.1$ & $81.1 \pm 6.4$ & $79.9 \pm 6.2$ & $81.3 \pm 6.9$ & $79.7 \pm 6.1$ & $80.5 \pm 7.4$ & $79.9 \pm 6.2$ & $81.3 \pm 5.9$ & $79.7 \pm 6.1$ \\
\hline Men & $9(50.0)$ & $489(57.8)$ & $5(38.5)$ & $431(55.4)$ & $7(70.0)$ & $482(57.9)$ & $12(75.0)$ & $418(55.5)$ & $19(67.9)$ & $448(57.7)$ & $13(56.5)$ & $379(54.8)$ \\
\hline STS score $(\%)$ & $5.0 \pm 1.6$ & $4.4 \pm 1.5$ & $4.7 \pm 1.5$ & $4.5 \pm 1.6$ & $5.5 \pm 2.0^{*}$ & $4.4 \pm 1.5^{*}$ & $5.2 \pm 2.0$ & $4.5 \pm 1.6$ & $5.1 \pm 1.6^{*}$ & $4.4 \pm 1.5^{*}$ & $5.1 \pm 2.1$ & $4.5 \pm 1.6$ \\
\hline $\mathrm{SCr}>2 \mathrm{mg} / \mathrm{dL}$ & $1(5.6)$ & $13(1.5)$ & $0(0.0)$ & $17(2.2)$ & $0(0.0)$ & $13(1.6)$ & $2(12.5)$ & $15(2.0)$ & $1(3.6)$ & $12(1.5)$ & $0(0.0)$ & $14(2.0)$ \\
\hline $\begin{array}{l}\text { Peripheral vascular } \\
\text { disease }\end{array}$ & $6(33.3)$ & $260(30.7)$ & $3(23.1)$ & $232(29.8)$ & $5(50.0)$ & $253(30.4)$ & $7(43.8)$ & $222(29.5)$ & $9(32.1)$ & 238 (30.6) & $5(21.7)$ & 203 (29.4) \\
\hline $\begin{array}{l}\text { Cerebrovascular } \\
\text { disease }\end{array}$ & $4(22.2)$ & 147 (17.4) & $6(46.2)^{*}$ & $123(15.8)^{*}$ & $2(20.0)$ & $145(17.4)$ & $4(25.0)$ & $119(15.8)$ & $5(17.9)$ & $136(17.5)$ & $4(17.4)$ & $110(15.9)$ \\
\hline $\begin{array}{l}\text { Chronic lung } \\
\text { disease }\end{array}$ & $6(33.3)$ & $299(35.4)$ & $4(30.8)$ & $263(33.8)$ & $4(40.0)$ & $292(35.1)$ & $8(50.0)$ & $251(33.3)$ & $11(39.3)$ & $271(35.0)$ & $6(26.1)$ & $233(33.7)$ \\
\hline $\begin{array}{l}\text { Coronary artery } \\
\text { disease }\end{array}$ & $13(72.2)$ & $528(62.4)$ & $7(53.8)$ & $500(64.3)$ & $6(60.0)$ & $520(62.4)$ & $12(75.0)$ & $483(64.1)$ & $21(75.0)$ & $482(62.0)$ & $13(56.5)$ & $442(64.0)$ \\
\hline $\begin{array}{l}\text { Pre-existing } \\
\text { PPI/ICD }\end{array}$ & $2(11.1)$ & $85(10.0)$ & $0(0.0)$ & $79(10.2)$ & $1(10.0)$ & $84(10.1)$ & $2(12.5)$ & $77(10.2)$ & $5(17.9)$ & $75(9.7)$ & $5(21.7)$ & $70(10.1)$ \\
\hline $\begin{array}{l}\text { Atrial fibrillation/ } \\
\text { flutter }\end{array}$ & $6(33.3)$ & $237(28.0)$ & $4(30.8)$ & $206(26.5)$ & $4(40.0)$ & 232 (27.9) & $7(43.8)$ & $198(26.3)$ & $12(42.9)$ & $210(27.0)$ & $13(56.5)^{*}$ & $177(25.6)^{*}$ \\
\hline Home oxygen & $1(5.6)$ & $17(2.0)$ & $2(15.4)^{*}$ & $19(2.4)^{*}$ & $0(0.0)$ & $17(2.0)$ & $1(6.3)$ & $17(2.3)$ & $2(7.1)$ & $13(1.7)$ & $1(4.3)$ & $14(2.0)$ \\
\hline $\begin{array}{l}\text { 5-m gait } \\
\quad \text { speed }>6 \mathrm{~s}\end{array}$ & $8(53.3)$ & $420(51.7)$ & $6(50.0)$ & $396(53.2)$ & $5(50.0)$ & $413(51.7)$ & $7(46.7)$ & $383(53.0)$ & $14(51.9)$ & $387(52.0)$ & $9(42.9)$ & $352(53.0)$ \\
\hline Falls in past $6 \mathrm{mo}$ & $2(11.1)$ & $100(11.8)$ & $2(15.4)$ & 99 (12.7) & $1(10.0)$ & 99 (11.9) & $3(18.8)$ & $96(12.8)$ & $3(10.7)$ & $93(12.0)$ & $1(4.3)$ & $91(13.2)$ \\
\hline $\begin{array}{l}\geq 2 \text { KATZ ADL } \\
\text { deficits }\end{array}$ & $1(5.6)$ & $8(0.9)$ & $0(0.0)$ & $7(0.9)$ & $0(0.0)$ & $8(1.0)$ & $0(0.0)$ & $7(0.9)$ & $0(0.0)$ & $8(1.0)$ & $1(4.3)$ & $6(0.9)$ \\
\hline \multicolumn{13}{|l|}{ Procedural } \\
\hline $\begin{array}{l}\text { Procedure } \\
\text { time (min) }\end{array}$ & $93.8 \pm 62.3^{*}$ & $51.6 \pm 31.5^{*}$ & $219.5 \pm 110.9$ & $203.6 \pm 68.3$ & $81.3 \pm 72.5$ & $51.1 \pm 30.5$ & $211.6 \pm 57.4$ & $203.7 \pm 68.7$ & $54.7 \pm 25.0$ & $51.2 \pm 30.7$ & $228.9 \pm 66.6$ & $201.3 \pm 67.5$ \\
\hline $\begin{array}{l}\text { Concomitant } \\
\text { CABG or PCI } \dagger\end{array}$ & $6(35.3)^{*}$ & $122(14.4)^{*}$ & $4(30.8)$ & $169(21.8)$ & $1(10.0)$ & $120(14.4)$ & $3(18.8)$ & $166(22.1)$ & $7(25.0)$ & 108 (13.9) & $8(34.8)$ & $147(21.3)$ \\
\hline $\begin{array}{l}\text { TAV delivery } \\
\text { time (min) }\end{array}$ & $30.3 \pm 35.4$ & $14.7 \pm 15.2$ & - & - & $18.3 \pm 16.8$ & $14.6 \pm 15.1$ & - & - & $20.3 \pm 24.7$ & $14.4 \pm 14.6$ & - & - \\
\hline
\end{tabular}




\begin{tabular}{|c|c|c|c|c|c|c|c|c|c|c|c|c|}
\hline & \multicolumn{4}{|c|}{0 to $30 \mathrm{~d}$} & \multicolumn{4}{|c|}{31 to $120 \mathrm{~d}$} & \multicolumn{4}{|c|}{121 to $365 \mathrm{~d}$} \\
\hline & \multicolumn{2}{|c|}{ TAVR } & \multicolumn{2}{|c|}{ SAVR } & \multicolumn{2}{|c|}{ TAVR } & \multicolumn{2}{|c|}{ SAVR } & \multicolumn{2}{|c|}{ TAVR } & \multicolumn{2}{|c|}{ SAVR } \\
\hline & $\begin{array}{c}\text { Dead } \\
(n=18)\end{array}$ & $\begin{array}{c}\text { Alive } \\
(\mathrm{n}=\mathbf{8 4 6})\end{array}$ & $\begin{array}{c}\text { Dead } \\
(\mathbf{n}=\mathbf{1 3})\end{array}$ & $\begin{array}{c}\text { Alive } \\
(\mathbf{n}=\mathbf{7 7 8})\end{array}$ & $\begin{array}{c}\text { Dead } \\
(\mathbf{n}=\mathbf{1 0})\end{array}$ & $\begin{array}{c}\text { Alive } \\
(\mathbf{n}=\mathbf{8 3 3})\end{array}$ & $\begin{array}{c}\text { Dead } \\
(\mathrm{n}=16)\end{array}$ & $\begin{array}{c}\text { Alive } \\
(\mathrm{n}=\mathbf{7 5 3})\end{array}$ & $\begin{array}{c}\text { Dead } \\
(\mathbf{n}=\mathbf{2 8})\end{array}$ & $\begin{array}{c}\text { Alive } \\
(\mathbf{n}=777)\end{array}$ & $\begin{array}{c}\text { Dead } \\
(\mathbf{n}=\mathbf{2 3})\end{array}$ & $\begin{array}{c}\text { Alive } \\
(\mathrm{n}=691)\end{array}$ \\
\hline CPS time (min) & - & - & $127.1 \pm 106.7$ & $97.4 \pm 37.2$ & - & - & $105.8 \pm 40.0$ & $97.4 \pm 37.2$ & - & - & $110.5 \pm 43.7$ & $96.4 \pm 36.8$ \\
\hline $\begin{array}{l}\text { Crossclamp } \\
\text { time (min) }\end{array}$ & - & - & $74.2 \pm 52.1$ & $74.3 \pm 30.0$ & - & - & $84.8 \pm 32.8$ & $74.3 \pm 30.0$ & - & - & $75.4 \pm 32.6$ & $73.8 \pm 29.8$ \\
\hline More than 1 valve & $4(23.5)^{*}$ & $54(6.4)^{*}$ & - & - & $2(20.0)$ & $51(6.1)$ & - & - & $5(17.9)$ & $45(5.8)^{*}$ & - & - \\
\hline
\end{tabular}

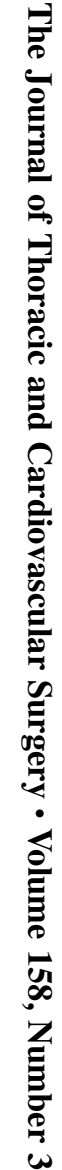
implanted

Values are presented as mean \pm standard deviation or $\mathrm{n}(\%)$. STS, Society of Thoracic Surgeons; $S C r$, serum creatinine; $P P I$, permanent pacemaker implantation; $I C D$, implantable cardioverter defibrillator; $A D L$, activities of daily living; $C P S$, cardiopulmonary bypass support. $* P<.05$ for dead versus alive. $\dagger$ Patients in the surgical group had concomitant coronary artery bypass grafting (CABG) and patients in the transcatheter group underwent percutaneous coronary intervention (PCI).

$\stackrel{\mathbb{N}}{\mathbb{2}}$ 